\title{
Quantificação de subpopulações linfocitárias no sangue do cordão umbilical de eqüinos
}

\author{
Quantification of lymphocyte subpopulations in equine umbilical cord blood
}

\author{
Roberta Ferro de Godoy ${ }^{I}$ Áureo Evangelista SantanaII Patrícia Bonini Palma ${ }^{\text {III }}$ \\ Fabiana Rossetto ${ }^{\mathrm{III}}$ José Victor de Oliveira $^{\mathrm{IV}}$
}

\section{RESUMO}

Este estudo visou a determinar os valores eritroleucométricos e quantificar as subpopulações linfocitárias no sangue do cordão umbilical (SCU) e no sangue jugular de eqüinos neonatos. Foi realizada a colheita de SCU e do sangue jugular de 20 potros ao nascimento. As amostras foram submetidas às determinações dos valores eritroleucométricos e à quantificação de subpopulações de linfócitos-T, pela técnica citofluorométrica. Não foram verificadas diferenças significativas $(P<0,05)$ entre os valores médios de tais parâmetros, entre o sangue jugular de neonatos e o SCU eqüino. $O$ valor total para neutrófilos segmentados, no SCU e na jugular dos neonatos, foi inferior ao reportado para eqüinos ao nascimento. As contagens de linfócitos CD5+ e CD4+ no SCU e jugular de neonatos eqüinos foram inferiores àquelas admitidas para o sangue periférico de eqüinos adultos, indicando um componente imunológico imaturo. No entanto, a contagem de linfócitos CD8+ foi semelhante à descrita em sangue periférico de eqüinos adultos. A proporção CD4:CD8 obtida nesse ensaio, tanto para o SCU $(2,64 \pm 0,91)$, como no sangue jugular de eqüinos neonatos $(2,41 \pm 0,81)$, demonstrou uma dominância das células T CD4+ sobre os linfócitos $T$ CD8+.

Palavras-chave: eqüinos, imunofenotipagem, citometria de fluxo, neonatos.

\section{ABSTRACT}

The objective of the present study was to determine erythometric and leukometic values and quantify subpopulations of lymphocytes in umbilical cord blood (UCB) and jugular blood of neonate foals. UCB and jugular blood

\begin{abstract}
were collected from 20 foals at birth and processed for determination of erythometric and leukometric values and quantification of subpopulations of $T$ lymphocytes by cytofluorometry. No significant difference $(P<0.05)$ was noted between average values in neonate jugular blood and equine UCB. Total values observed for segmented neutrophils in UCB and neonate jugular blood were lower than those reported for horses at birth. The quantity of $\mathrm{CD} 5+$ and $\mathrm{CD} 4+$ lymphocytes was lower in UCB and neonate jugular blood than in peripheral blood of adult horses, which indicates immunological immaturity. The frequency of CD8+ lymphocytes, however, was similar to that described for peripheral blood of adult horses. CD4:CD8 ratio observed in the present study both for UCB $(2.64 \pm 0.91)$ and for neonate jugular blood $(2.41 \pm 0.81)$ demonstrated the predominance of CD4+ T lymphocytes over CD8+ $T$ cells.
\end{abstract}

Key words: horses, immunophenotyping, cytofluorometry, neonates.

\section{INTRODUÇÃO}

A importância do estudo do sangue do cordão umbilical (SCU) foi verificada em trabalhos recentes, que têm demonstrado a presença de células tronco ("stem-cells") no sangue do cordão umbilical humano, representando uma fonte alternativa para reconstituição tecidual (GLUCKMAN et al., 1989). A distribuição das diferentes subpopulações linfocitárias e as características tintoriais dos linfócitos do $\mathrm{SCU}$

IPrograma de Pós-graduação em Cirurgia Veterinária, Departamento de Clínica e Cirurgia Veterinária, Faculdade de Ciências Agrárias e Veterinária (FCAV), Universidade Estadual Paulista (UNESP), Jaboticabal, SP, Brasil. E-mail: robertagodoy@yahoo.com.br. Autor para correspondência.

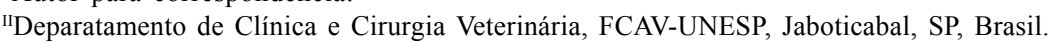

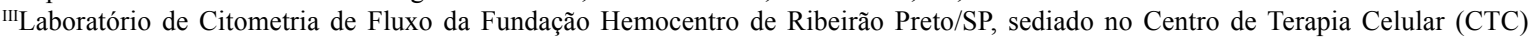

da Faculdade de Medicina de Ribeirão Preto da Universidade de São Paulo (FMRP/USP). Ribeirão Preto, SP, Brasil.

${ }^{\text {IV}}$ Pólo Regional de Desenvolvimento Tecnológico dos Agronegócios da Alta Mogiana-APTA, Colina, SP, Brasil. 
diferem daquelas do sangue periférico, em seres humanos. Ademais, a fenotipagem de linfócitos do SCU é facilmente realizada através da citometria de fluxo, técnica que quantifica células coradas com reagentes fluorescentes específicos (SCHUMACHER \& BURKHEAD, 2000).

Apesar da importância do sangue do cordão umbilical como fonte de células tronco e do advento da imunofenotipagem de linfócitos, ainda não existem muitos estudos sobre as células sangüíneas do cordão umbilical em animais domésticos. Estudos fazem referência à imunofenotipagem de linfócitos do sangue periférico de eqüinos (LUNN et al., 1991; BLANCHARDCHANNEL et al., 1994; KYDD et al., 1994; AKENS et al., 1997; BENDALI-AHCÈNE et al., 1997; LUNN et al., 1998). Entretanto, as características imunofenotípicas das células linfocitárias do SCU da referida espécie ainda não foram avaliadas.

Valores hematológicos (exceto o número de hemácias e a concentração de hemoglobina corpuscular média), subpopulações linfocitárias (CD3+, CD4+, $\mathrm{CD} 8+$ ) e células progenitoras hematopoéticas no SCU humano apresentaram-se mais elevados do que aqueles obtidos no sangue periférico de adultos sadios quando avaliados por contadores automáticos de células, esfregaços corados com Metanol May-Grunwald Giemsa (MMG), citometria de fluxo e culturas celulares semi-sólidas (RUBINSTEIN et al., 1995; CHAISIRIPOOMKERE et al., 1999).

As moléculas de superfície dos linfócitos do SCU humano foram estudadas por PRANKE et al. (2001) através da citometria de fluxo de duas cores. Os linfócitos $\mathrm{T}$ representaram $47 \%$ do total das células mononucleadas, sendo que os linfócitos $\mathrm{T}$ auxiliares (CD3+e CD4+) e citotóxicos (CD3+e CD8+) representaram 34 e $13 \%$ dos linfócitos, respectivamente.

Os valores fisiológicos de subpopulações linfocitárias no SCU humano foram estabelecidos por SZABOLCS et al. (2003) e foram comparados com os valores do sangue periférico de adultos. Encontrou-se um percentual maior de células imaturas, não apenas quanto às subpopulações $\mathrm{CD} 4+$ e $\mathrm{CD} 8+$, mas também quanto aos linfócitos $\mathrm{B}$.

Em eqüinos, o estudo pioneiro do SCU foi conduzido por GODOY (2003), que colheu o sangue do cordão umbilical e da jugular de potros ao nascimento, através da venipunção umbilical, determinando os valores eritroleucométricos e seroprotéicos. Os valores obtidos para tais variáveis no SCU de potros neonatos não apresentaram diferenças significativas em relação àqueles obtidos a partir da venipunção jugular dos mesmos animais, no momento do nascimento.

A citometria de fluxo permite a separação e contagem de células linfocitárias com base no tamanho e na intensidade de fluorescência das referidas células (ROITT et al., 2003). Os linfócitos de eqüinos podem ser tipificados com anticorpos monoclonais conjugados com isotiocianato de fluoresceína (FITC) ou ficoeritrina (PE). Os anticorpos monoclonais CVS5, CVS4 e CVS8 reagem, respectivamente, com as glicoproteínas CD5, CD4 e CD8 presentes na superfície dos linfócitos $\mathrm{T}$, linfócitos $\mathrm{T}$ auxiliares e linfócitos $\mathrm{T}$ citotóxicos/supressores (AKENS et al., 1997).

A análise do sangue total de eqüinos adultos, por meio da citometria de fluxo, permite quantificar os linfócitos T e B e as subpopulações linfocitárias. BENDALI-AHCÈNE et al. (1997) relataram que dentre as células linfocitárias, 30,2 (14\% são representados por linfócitos-B e 74,9 (8\% por linfócitos CD5+. Destes linfócitos, CD5+, 11,5 (1\% representam linfócitos CD8+e 55,4 (2\% linfócitos CD4+. A somatória de linfócitos CD4+ e CD8+, que representaria a totalidade dos linfócitos CD5+, mostrou-se levemente inferior à quantidade de linfócitos CD5+, pois há uma pequena porcentagem de linfócitos-B que expressa o antígeno CD5. Os valores absolutos para as diferentes subpopulações linfocitárias são estabelecidos com base na contagem global dos leucócitos e na fórmula linfocitária absoluta. Para os eqüinos, os valores descritos são: 3.960 linfócitos $\mathrm{mm}^{-3}, 1.057$ linfócitos-B $\mathrm{mm}^{-3}, 1.939$ linfócitos-T CD4+ $\mathrm{mm}^{-3}, 402$ linfócitos-T $\mathrm{CD} 8+\mathrm{mm}^{-3}, 2.621$ linfócitos $\mathrm{CD} 5+\mathrm{mm}^{-3}, 561$ células nulas $\mathrm{mm}^{-3}, 280$ linfócitos-B CD5+ [(CD5+)-(CD4++ CD8+)] $\mathrm{mm}^{-3}$ (BENDALI-AHCÈNE et al., 1995).

Idealizou-se o presente ensaio com o objetivo principal de avaliar um método de colheita de sangue do cordão umbilical em eqüinos neonatos sadios, determinar os valores hematológicos e quantificar as células linfocitárias pan-T e as subpopulações CD4 e CD8, no referido SCU, por meio da utilização de marcadores de superfície (anticorpos monoclonais), bem como do sangue central dos neonatos. $\mathrm{O}$ intuito foi estabelecer valores de referência para o SCU eqüino, compará-lo com o sangue central dos neonatos e obter informações sobre o desenvolvimento da capacidade imunológica dos eqüinos, particularmente, da imunocompetência do neonato.

\section{MATERIAL E MÉTODOS}

Amostras do sangue da jugular de 20 neonatos eqüinos da raça Brasileira de Hipismo (grupo E1) e do sangue do cordão umbilical (SCU) dos 
respectivos neonatos (grupo E2) foram colhidos, em tubos com EDTA, imediatamente após o nascimento. As amostras foram submetidas a estudos eritroleucométricos com o auxílio do contador automático de células ACT Coulter e de esfregaços sangüíneos.

Os estudos citofluorométricos foram realizados em um prazo máximo de 24 horas. Inicialmente foi feita a identificação de quatro tubos estéreis para cada amostra. Em cada tubo, foram adicionados $100 \mu \mathrm{L}$ de sangue total e $10 \mu \mathrm{L}$ dos respectivos reagentes: controle negativo ã1RPE (MCA928, Serotec) no tubo 1; anticorpo monoclonal eqüino anti-CD4 ${ }^{+}$(MCA1078, Serotec) no tubo 2; anticorpo monoclonal eqüino anti$\mathrm{CD5}^{+}$(MCA1079, Serotec) no tubo 3; e anticorpo monoclonal eqüino anti-CD8 ${ }^{+}\left(M_{C A} 2385\right.$, Serotec) no tubo 4. Os tubos foram incubados por 15 minutos, à temperatura ambiente, no escuro.

Adicionou-se $1 \mathrm{~mL}$ de tampão de lise de hemácias (FACS Lysing Solution, Becton Dickinson) em cada tubo, seguido de homogeneização. Os tubos foram então incubados por 10 minutos, à temperatura ambiente, no escuro. A suspensão de células foi centrifugada (IEC Centra CL2 Centrifuge, Thermo Electron Corporation) a 1800rpm, por 3 minutos, o sobrenadante foi descartado e adicionaram-se $2 \mathrm{~mL}$ de solução salina tamponada com fosfato $0,01 \mathrm{M} \mathrm{e} \mathrm{pH}$ entre 7,4 e 7,6 (PBS). Este procedimento, ou seja, a lavagem da suspensão de células, foi repetido duas vezes.

Após a segunda lavagem das células, foram adicionados $5 \mu \mathrm{L}$ do anticorpo secundário $\left(\mathrm{F}(\mathrm{ab})_{2}\right.$ rabbit anti-mouse IgG:RPE) conjugado ao fluorocromo RPE (R ficoeritrina) (STAR12A, Serotec). Os tubos foram incubados novamente, durante 15 minutos, à temperatura ambiente, no escuro. Adicionaram-se $2 \mathrm{~mL}$ de PBS e realizou-se o procedimento e lavagem das células novamente. Após o descarte do sobrenadante na última lavagem, as células foram ressuspendidas com $400 \mu \mathrm{L}$ de PBS.

As amostras foram submetidas à análise no citofluorômetro (FACS Calibur, Becton Dickinson) para identificação e contagem das subpopulações linfocitárias.

Os dados lidos no citômetro de fluxo foram analisados por um programa de computador (Cell Quest Pro Software, Becton Dickinson), que forneceu o histograma e a tabela com a quantidade de células detectadas pela imunofenotipagem.

Os dados obtidos foram tabulados e submetidos à análise estatística descritiva simples, seguida do teste $t(\mathrm{P}<0,05)$ para a devida confrontação entre as médias dos dois grupos (SNEDECOR; COCHRAN, 1987).

\section{RESULTADOS}

Os valores médios e os desvios-padrão obtidos para as contagens globais de hemácias, a concentração de hemoglobina, o volume globular (VG), o volume corpuscular médio (VCM) e a concentração de hemoglobina corpuscular média (CHCM), nos dois grupos estudados, estão apresentados na tabela 1 .

Os valores médios e os desvios-padrão obtidos para as contagens globais de leucócitos, neutrófilos bastonetes, neutrófilos segmentados, linfócitos e monócitos, nos dois grupos estudados, estão apresentados na tabela 2.

Os valores médios e os desvios-padrão obtidos para as contagens de células $\mathrm{CD}^{+}, \mathrm{CD}^{+}, \mathrm{CD}^{+}$ e razão $\mathrm{CD}^{+}: \mathrm{CD}^{+}$, obtidos por meio da citometria de fluxo em neonatos eqüinos (E1) e SCU eqüino (E2), estão apresentados na tabela 3 .

\section{DISCUSSÃO}

Os valores médios obtidos na contagem global de hemácias, no sangue da jugular de eqüinos neonatos (E1) $\left(9,02 \pm 0,61 \times 106\right.$ células $\left.\mu \mathrm{L}^{-1}\right)$, apresentaram-se levemente abaixo daqueles considerados fisiológicos para potros ao nascimento (HARVEY, 1990). No SCU eqüino (E2), os valores médios obtidos na contagem global de hemácias $\left(9,06 \pm 0,38 \times 106\right.$ células $\left.\mu \mathrm{L}^{-1}\right)$ também se mostraram levemente inferiores à faixa de normalidade reportada para potros ao nascimento por alguns autores, dentre os quais HARVEY et al. (1987) e HARVEY (1990). Neste experimento, tanto o sangue jugular (E1) quanto o SCU (E2) de neonatos eqüinos apresentaram valores médios nas contagens globais de hemácias dentro da faixa de normalidade proposta por JAIN (1986) para eqüinos adultos. Achado divergente foi relatado por PRANKE et al. (2001), em humanos, cujo número de hemácias revelou-se maior no SCU do que naquele obtido a partir da veia braquiocefálica de adultos.

Com relação ao volume globular, o sangue da jugular (E1) $(37,44 \pm 1,31 \%)$ e aquele do cordão umbilical (E2) $(38,56 \pm 1,07 \%)$ de neonatos eqüinos apresentaram valores médios ligeiramente mais baixos do que aqueles reportados para potros ao nascimento (HARVEY, 1990). Ademais, conforme asseverado por esses mesmos autores, o volume globular nos potros ao nascimento é muito similar ao dos eqüinos adultos, o que concorda com os valores médios obtidos para volume globular no sangue da jugular (E1) e do cordão umbilical (E2) de eqüinos neonatos, neste experimento. De outra parte, tais assertivas não são válidas para humanos, já que o volume globular obtido no SCU 
Tabela 1 - Valores médios e respectivos desvios-padrão de contagem global de hemácias, concentração de hemoglobina, volume globular, VCM e CHCM, em neonatos eqüinos (E1) e SCU eqüino (E2). Jaboticabal (SP), 2005.*.

\begin{tabular}{|c|c|c|c|c|c|c|c|c|c|c|}
\hline \multirow[t]{2}{*}{ Grupos } & \multicolumn{2}{|c|}{ 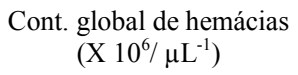 } & \multicolumn{2}{|c|}{$\begin{array}{l}\text { Conc. De hemoglobina } \\
\qquad\left(\mathrm{g} \mathrm{dL}^{-1}\right)\end{array}$} & \multicolumn{2}{|c|}{ Volume globular (\%) } & \multicolumn{2}{|c|}{ VCM (fL) } & \multicolumn{2}{|c|}{ CHCM ( $\left.\mathrm{g} \mathrm{dL}^{-1}\right)$} \\
\hline & Média & $\begin{array}{l}\text { Desvio } \\
\text { padrão }\end{array}$ & Média & $\begin{array}{l}\text { Desvio } \\
\text { padrão }\end{array}$ & Média & $\begin{array}{l}\text { Desvio } \\
\text { padrão }\end{array}$ & Média & $\begin{array}{l}\text { Desvio } \\
\text { padrão }\end{array}$ & Média & $\begin{array}{l}\text { Desvio } \\
\text { padrão }\end{array}$ \\
\hline E1 & $9,02 \mathrm{~A}$ & 0,61 & $13,23 \mathrm{~A}$ & 0,66 & $37,44 \mathrm{~A}$ & 1,31 & $41,67 \mathrm{~A}$ & 3,25 & $35,37 \mathrm{~A}$ & 2,04 \\
\hline E2 & $9,06 \mathrm{~A}$ & 0,38 & $13,12 \mathrm{~A}$ & 0,39 & $38,56 \mathrm{~A}$ & 1,07 & $42,62 \mathrm{~A}$ & 1,97 & $34,09 \mathrm{~A}$ & 3,13 \\
\hline
\end{tabular}

*Médias de uma mesma coluna seguidas por letras maiúsculas iguais não diferem entre si $(\mathrm{P}<0,05)$ e estabelecem a comparação entre grupos:

E1- Sangue da jugular de neonatos eqüinos;

E2- Sangue do cordão umbilical eqüino.

humano suplanta aquele obtido no sangue da braquiocefálica de adultos, da espécie em questão (RUBINSTEIN et al., 1995; CHAISIRIPOOMKERE et al., 1999).

Os resultados obtidos para o volume corpuscular médio (VCM) mostraram que, para este parâmetro, o sangue da jugular (E1) $(41,67 \pm 3,25 \mathrm{fL})$ e do cordão umbilical de eqüinos neonatos (E2) $(42,62 \pm 1,97 \mathrm{fL})$ apresentaram valores médios de VCM dentro da normalidade para neonatos eqüinos. Ademais, estes valores também se enquadram no padrão de normalidade para eqüinos adultos (JAIN, 1986). HARVEY (1990) refere-se a valores de VCM, em potros, ao nascimento, similares aos encontrados em adultos, uma vez que, ao nascimento, os eritroblastos e reticulócitos estão ausentes no sangue periférico da referida espécie. Tais achados diferem daqueles relatados em humanos por RUBINSTEIN et al. (1995), CHAISIRIPOOMKERE et al. (1999) e PRANKE et al. (2001), que se referem a VCM no SCU humano superior àquele encontrado no sangue da braquiocefálica de humanos adultos, devido à presença de eritroblastos $\mathrm{e}$ reticulócitos no SCU da referida espécie.

Com relação à concentração de hemoglobina corpuscular média (CHCM), os valores médios obtidos no sangue da jugular (E1) $(35,37 \pm 2,04 \mathrm{~g}$
$\left.\mathrm{dL}^{-1}\right)$ e do cordão umbilical (E2) $\left(34,09 \pm 3,13 \mathrm{~g} \mathrm{dL}^{-1}\right) \mathrm{de}$ eqüinos neonatos apresentaram-se dentro da variação fisiológica reportada para potros ao nascimento (HARVEY, 1990) e adultos (JAIN, 1986), corroborando com os dados observados por HARVEY (1990).

Os valores médios obtidos para contagens globais de leucócitos no SCU eqüino (E2) $(5,68 \pm 0,76 \mathrm{x}$ 103 células $\mu \mathrm{L}^{-1}$ ) e na jugular de neonatos eqüinos (E1) $\left(6,29 \pm 0,74 \times 103\right.$ células $\left.\mu \mathrm{L}^{-1}\right)$ concordam com os valores reportados por HARVEY (1990). As contagens médias de células leucocitárias, nos referidos grupos (E1 e E2), mostraram-se no limite inferior dos valores fisiológicos para eqüinos adultos, conforme HARVEY (1990) e GODOY (2003) reportaram, ou seja, os valores para leucócitos totais de eqüinos ao nascimento são levemente menores que aqueles de eqüinos adultos. GODOY (2003) afirmou não haver diferença significativa entre a contagem de leucócitos do SCU, quando comparada àquela da jugular de eqüinos neonatos, fato reafirmado no experimento em questão.

Os leucócitos basofílicos e eosinofílicos mostraram-se ausentes no sangue da jugular (E1) e do cordão umbilical (E2) de eqüinos neonatos, assim como reportou GODOY (2003), o que corrobora os achados de JAIN (1986) e HARVEY (1990), segundo os quais, freqüentemente, tais células estão ausentes no sangue

Tabela 2 - Valores médios e respectivos desvios-padrão de contagem de leucócitos, neutrófilos bastonetes, neutrófilos segmentados, linfócitos e monócitos, em neonatos eqüinos (E1) e SCU eqüino (E2). Jaboticabal (SP), 2005.*

\begin{tabular}{|c|c|c|c|c|c|c|c|c|c|c|}
\hline \multirow[t]{2}{*}{ GRUPOS } & \multicolumn{2}{|c|}{$\begin{array}{l}\text { Cont. global de } \\
\text { leucócitos } \\
\left(\mathrm{X} 10^{3} \mu \mathrm{L}^{-1}\right)\end{array}$} & \multicolumn{2}{|c|}{$\begin{array}{l}\text { Neutrófilos bastonetes } \\
\qquad\left(\mathrm{X} 10^{3} \mu \mathrm{L}^{-1}\right)\end{array}$} & \multicolumn{2}{|c|}{$\begin{array}{l}\text { Neutrófilos } \\
\text { segmentados } \\
\left(\mathrm{X} 10^{3} \mu \mathrm{L}^{-1}\right)\end{array}$} & \multicolumn{2}{|c|}{$\begin{array}{l}\text { Linfócitos } \\
\left(\mathrm{X} 10^{3} \mu \mathrm{L}^{-1}\right)\end{array}$} & \multicolumn{2}{|c|}{$\begin{array}{l}\text { Monócitos } \\
\left(\mathrm{X} 10^{3} \mu \mathrm{L}^{-1}\right)\end{array}$} \\
\hline & Média & $\begin{array}{l}\text { Desvio } \\
\text { padrão }\end{array}$ & Média & $\begin{array}{l}\text { Desvio } \\
\text { padrão }\end{array}$ & Média & $\begin{array}{l}\text { Desvio } \\
\text { padrão }\end{array}$ & Média & $\begin{array}{l}\text { Desvio } \\
\text { padrão }\end{array}$ & Média & $\begin{array}{l}\text { Desvio } \\
\text { padrão }\end{array}$ \\
\hline E1 & $6,29 \mathrm{~A}$ & 0,74 & $0,03 \mathrm{~A}$ & 0,03 & 2,99 A & 0,60 & $3,21 \mathrm{~A}$ & 0,56 & $1,22 \mathrm{~A}$ & 0,97 \\
\hline E2 & $5,68 \mathrm{~A}$ & 0,76 & $0,03 \mathrm{~A}$ & 0,03 & $2,72 \mathrm{~A}$ & 0,61 & $2,86 \mathrm{~A}$ & 0,26 & $1,11 \mathrm{~A}$ & 1,05 \\
\hline
\end{tabular}

*Médias de uma mesma coluna seguidas por letras maiúsculas iguais não diferem entre si $(\mathrm{P}<0,05)$ e estabelecem a comparação entre grupos:

E1-Sangue da jugular de neonatos eqüinos;

E2- Sangue do cordão umbilical eqüino. 


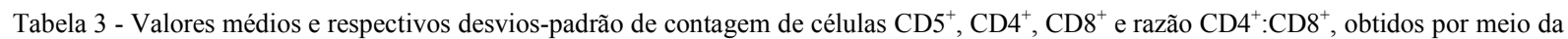
citometria de fluxo em neonatos eqüinos (E1) e SCU eqüino (E2). Jaboticabal (SP), 2005.*

\begin{tabular}{lcccccccc}
\hline & \multicolumn{2}{c}{$\mathrm{CD}^{+}\left(\right.$células $\left.\mu \mathrm{L}^{-1}\right)$} & \multicolumn{2}{c}{$\mathrm{CD}^{+}\left(\right.$células $\left.\mu \mathrm{L}^{-1}\right)$} & \multicolumn{2}{c}{$\mathrm{CD}^{+}\left({\left.\text {células } \mu \mathrm{L}^{-1}\right)}^{2}\right.$} & $\mathrm{CD}^{+}: \mathrm{CD}^{+}$ \\
\cline { 2 - 8 } & Média & Desvio padrão & Média & Desvio padrão & Média & Desvio padrão & Média & Desvio padrão \\
\hline E1 & $1621 \mathrm{~A}$ & 410,69 & $1001 \mathrm{~A}$ & 166,02 & $473 \mathrm{~A}$ & 230,19 & $2,41 \mathrm{~A}$ & 0,81 \\
E2 & $1429 \mathrm{~A}$ & 234,49 & $918 \mathrm{~A}$ & 142,43 & $381 \mathrm{~A}$ & 118,42 & $2,64 \mathrm{~A}$ & 0,91 \\
\hline
\end{tabular}

*Médias de uma mesma coluna seguidas por letras maiúsculas iguais não diferem entre si $(P<0,05)$ e estabelecem a comparação entre grupos:

E1-Sangue da jugular de neonatos eqüinos;

E2- Sangue do cordão umbilical eqüino.

circulante em potros ao nascimento, sendo que os eosinófilos só aparecem no sangue circulante de eqüinos neonatos, aos sete dias de idade.

As contagens absolutas de neutrófilos segmentados no sangue da jugular (E1) $(2,99 \pm 0,60 \mathrm{x}$ 103 células $\left.\mu \mathrm{L}^{-1}\right)$ e umbilical (E2) $(2,72 \pm 0,61 \times 103$ células $\left.\mu \mathrm{L}^{-1}\right)$ de neonatos eqüinos se situaram na margem inferior dos valores propostos como normais para eqüinos adultos por JAIN (1986), concordando com as observações de HARVEY (1990) e GODOY (2003).

As contagens absolutas de linfócitos no sangue da jugular (E1) $\left(3,21 \pm 0,56 \times 103\right.$ células $\left.\mu \mathrm{L}^{-1}\right) \mathrm{e}$ umbilical (E2) $\left(2,86 \pm 0,26 \times 103\right.$ células $\left.\mu \mathrm{L}^{-1}\right)$ de neonatos eqüinos acompanharam os valores fisiológicos para células linfocitárias em potros ao nascimento (JAIN, 1986; HARVEY, 1990; GODOY, 2003). Tal como ocorreu com as demais variáveis leucocitárias, não houve diferenças nas contagens absolutas de linfócitos entre os grupos E1 e E2, como descrito por GODOY (2003).

Em imuno-hematologia humana, o estudo da função das células T no SCU tem importância considerável, de modo que inúmeras pesquisas têm sido conduzidas para estabelecer as características imunofenotípicas de populações e subpopulações linfocitárias no SCU (SCHUMACHER \& BURKHEAD, 2000; PRANKE et al., 2001; SZABOLCS et al., 2003). Embora existam relatos de imunofenotipagem de linfócitos no sangue periférico de eqüinos adultos (LUNN et al., 1991; BLANCHARD-CHANNEL et al., 1994; KYDD et al., 1994; AKENS et al., 1997; BENDALIAHCÈNE et al., 1995; 1997), não existiam estudos sobre as características imunofenotípicas dos linfócitos do SCU e da jugular de eqüinos neonatos.

Os valores médios obtidos para a contagem de linfócitos $\mathrm{CD}^{+}$no SCU (E2) (1429 $\pm 234,49$ células $\left.\mu \mathrm{L}^{-1}\right)$ e da jugular (E1) $\left(1621 \pm 410,69\right.$ células $\left.\mu \mathrm{L}^{-1}\right)$ mostraram-se inferiores àqueles obtidos por BENDALIAHCÈNE et al. (1995) no sangue periférico de eqüinos adultos (2621 células $\mu \mathrm{L}^{-1}$ ). Com relação aos linfócitos
$\mathrm{CD}^{+}$e CD$^{+}$no SCU (E2) $\left(918 \pm 142,43\right.$ células $\mu \mathrm{L}^{-1} \mathrm{e}$ $381 \pm 118,42$ células $\mu \mathrm{L}^{-1}$, respectivamente) e da jugular (E1) $\left(1001 \pm 166,02\right.$ células $\mu \mathrm{L}^{-1}$ e $473 \pm 230$, 19 células $\mu \mathrm{L}^{-1}$, respectivamente), estes igualmente se mostraram inferiores aos valores obtidos no sangue periférico de eqüinos adultos (1939 células $\mu \mathrm{L}^{-1}$ e 402 células $\mu \mathrm{L}^{-1}$, respectivamente) por BENDALI-AHCÈNE et al. (1995).

A somatória de linfócitos $\mathrm{CD}^{+}{ }^{+} \mathrm{CD}^{+}$, que representaria a totalidade dos linfócitos $\mathrm{CD}^{+}$, mostrouse levemente inferior à quantidade de linfócitos $\mathrm{CD}^{+}$, haja vista o fato de que há uma pequena porcentagem de linfócitos-B que expressa o antígeno CD5, conforme relataram BENDALI-AHCÈNE et al. (1997).

Os resultados obtidos neste ensaio discordam dos estudos realizados em imunohematologia humana, no fato de que os mesmos relataram menor quantidade de células pan-T, Tauxiliares e T-citotóxicas no SCU, comparadas àquelas encontradas no sangue periférico de neonatos. Porém, corroboram os achados em humanos, que relatam que as células pan-T, T-auxiliares e T-citotóxicas se encontaram em menor quantidade no $\mathrm{SCU}$, quando comparadas com o sangue periférico de adultos humanos (SCHULTZ et al., 2000).

\section{CONCLUSÕES}

O SCU e da jugular de eqüinos neonatos apresenta balanço eritroleucométrico e imunohematológico, em relação às subpopulações linfocitárias, diferente daquele encontrado no sangue de eqüinos adultos. Os valores obtidos para variáveis citológicas, a partir do SCU de eqüinos, não diferem daqueles obtidos no sangue da jugular dos referidos neonatos, sendo, portanto, úteis para a avaliação do quadro citológico em neonatos da espécie eqüina. As contagens global $\left(\mathrm{CD5}^{+}\right)$e sub-populacionais $\left(\mathrm{CD}^{+} \mathrm{e}\right.$ $\mathrm{CD}^{+}$) de linfócitos $\mathrm{T}$ no SCU e da jugular de eqüinos neonatos demonstraram predomínio dos linfócitos $\mathrm{T}$ auxiliares sobre os citotóxicos. 


\section{REFERÊNCIAS}

AKENS, M.K. et al. Comparative analyses of equine lymphocyte subsets in whole blood and gradient-purified samples. Veterinary Immunology and Immunopathology, Amsterdam, v.58, n.3-4, p.231-237, 1997.

BENDALI-AHCÈNE, S. et al. Flow cytometric analysis of blood lymphocyte phenotypes in horses infected with the equine infectious anemia virus. Journal of Equine Veterinary Science, Wildomar, v.15, n.8, p.360-364, 1995.

BENDALI-AHCÈNE, S. et al. Lymphocyte phenotypes, apoptosis and anti-nuclear antibodies in asymptomatic horses infected by equine infectious anemia virus. Revue de Médicine Vétérinaire, Toulouse, v.148, n.6, p.531-536, 1997.

BLANCHARD-CHANNEL, M. et al. Characterization of monoclonal antibodies specific for equine homologues of CD3 and CD5. Immunology, Oxford, v.82, n.3, p.548-554, 1994.

CHAISIRIPOOMKERE, W. et al. Study of hematopoietic progenitor cells, hematological values and lymphocyte subsets in cord blood: application for cord blood transplantation. Southeast Asian Journal of Tropical Medicine Public Health, Bangkok, v.30, n.4, p.781-785, 1999.

GLUCKMAN, E. et al. Hematopoietic reconstitution in a patient with Fanconi's anemia by means of umbilical-cord blood from an HLA-identical sibling. New England Journal of Medicine, Waltham, v.321, n.17, p.1174-1178, 1989.

GODOY, R.F. Estudo eritroleucométrico e proteinograma do sangue do cordão umbilical e da jugular de eqüinos e asininos ao nascimento e de suas respectivas mães. 2003. 64f. Dissertação (Mestrado em Cirurgia Veterinária) - Faculdade de Ciências Agrárias e Veterinárias, Universidade Estadual Paulista, Jaboticabal.

HARVEY, J.W. et al. Serum ferritin, serum iron and erythrocyte values in foals. American Journal of Veterinary Research, Chicago, v.48, n.9, p.1348-1353, 1987.

HARVEY, J.W. Normal hematologic values. In: KOTERBA, A.M. et al. Equine clinical neonatology. Philadelphia: Lea \& Febiger, 1990. p.561-570.
JAIN, N.C. Schalm's veterinary hematology. 4.ed. Philadelphia: Lea \& Febiger, 1986. 1221p.

KYDD, J. et al. Report of the first international workshop on equine leukocyte antigens. Veterinary Immunology and Immunopathology, Amsterdam, v.42, n.1, p.3-60, 1994.

LUNN, D.P. et al. Three monoclonal antibodies identifying antigens on all equine $\mathrm{T}$ lymphocytes, and two mutually exclusive T-lymphocyte subsets. Immunology, Oxford, v.74, n.2, p.251257, 1991.

LUNN, D.P. et al. Report of the second equine leucocyte antigen workshop, Squaw Valley, California, July 1995. Veterinary Immunology and Immunopathology, Amsterdam, v.62, n.2, p.101-143, 1998.

PRANKE, P. et al. Hematologic and immunophenotypic characterization of human umbilical cord blood. Acta Haematologica, Basel, v.105, n.4, p.71-76, 2001.

ROITT, I. et al. Imunologia. 7.ed. São Paulo: Manole, 2003. $481 \mathrm{p}$.

RUBINSTEIN, P. et al. Processing and cryopreservation of placental/umbilical cord blood for unrelated bone marrow reconstitution. Proceedings of the National Academy of Sciences of the United States of America, Washington, v.22, n.92, p.1019-1022, 1995

SCHULTZ et al. Maturational changes of lymphocyte surface antigens in human blood: comparison between fetuses, neonates and adults. Biology of the Neonate, Basel, v.78, n.2, p.7782, 2000 .

SCHUMACHER, M.J.; BURKHEAD, T. Stability of fresh and preserved fetal and adult lymphocyte cell surface markers. Journal of Clinical Laboratory Analysis, New York, v.14, n.6, p.320-326, 2000

SNEDECOR, G.W.; COCHRAN, W.G. Statistical methods 6.ed. Ames: Iowa State University, 1987. 593p.

SZABOLCS, P. et al. Coexistent naive phenotype and higher cycling rate of cord blood T-cells as compared to adult peripheral blood. Experimental Hematology, Amsterdam, v.31, p.708714, 2003 